\title{
Rescue extracorporeal membrane oxygenation therapy in methamphetamine toxicity
}

\author{
Laura K. Morrison, MD*; J Kromm ${ }^{\dagger}$; J Gaudet ${ }^{\dagger}$; D Zuege ${ }^{\dagger}$; B Button ${ }^{\ddagger}$; F Warshawski ${ }^{\dagger}$; SN Lucyk ${ }^{\ddagger \S}$
}

\begin{abstract}
Complications related to methamphetamine use and abuse are common presentations seen in the emergency department. Standard management focuses on addressing the central nervous system and cardiovascular effects with the use of sedation and hemodynamic support. We describe a case report of a patient with methamphetamine toxicity and subsequent severe cardiomyopathy refractory to conventional management that responded to cardiovascular support with extracorporeal membrane oxygenation therapy (ECMO). A 22-year-old female was admitted in severe cardiogenic shock following intravenous administration of methamphetamine and oral fentanyl use. Despite aggressive treatment with benzodiazepines, intravenous fluids, vasopressors, vasodilators, antibiotics and inotropes, the patient's clinical status deteriorated, and she suffered a cardiac arrest. The patient was successfully resuscitated, and following the return of spontaneous circulation, ECMO was initiated. After 82 hours the patient was successfully weaned from ECMO with the recovery of her left ventricular function and no neurologic sequelae. The patient developed leg ischemia requiring embolectomy and open repair as a complication of ECMO cannulation. In our case, ECMO was used successfully in treating severe cardiac dysfunction from acute methamphetamine-induced cardiomyopathy and was used as a bridge to recovery. The complications seen in this patient emphasize the potential risks associated with this intervention and highlight the need for careful patient selection.
\end{abstract}

\section{RÉSUMÉ}

Les complications liées à la consommation et à l'usage abusif des méthamphétamines sont chose courante au service des urgences. Le traitement habituel consiste principalement en la protection du système nerveux central et en la neutralisation des effets cardiovasculaires par la sédation et l'assistance hémodynamique. Sera exposé ici un cas d'intoxication aux méthamphétamines, accompagnée d'une cardiomyopathie grave, réfractaire au traitement usuel, qui a réagi favorablement à l'assistance cardiovasculaire à l'aide de l'oxygénation par circulation extracorporelle (OCEC) sur oxygénateur à membrane. Une jeune femme de 22 ans a été admise à l'hôpital en état de choc cardiogénique grave, suivant l'administration intraveineuse de méthamphétamines et la prise de fentanyl par voie orale. Malgré un traitement énergique, composé de benzodiazépines, de l'administration intraveineuse de liquides, de vasopresseurs, de vasodilatateurs, d'antibiotiques et d'inotropes, l'état clinique de la patiente a continué à se détériorer et il s'en est suivi un arrêt cardiaque. Après des manœuvres de réanimation couronnées de succès et un retour spontané à la circulation sanguine, nous avons entrepris l'OCEC. La patiente a été sevrée du traitement au bout de 82 heures, et ce, sans séquelles neurologiques; le fonctionnement ventriculaire gauche s'est également rétabli. Toutefois, une ischémie nécessitant une embolectomie et une réparation chirurgicale s'est développée dans la jambe, complication de la canulation. Dans le cas décrit ici, le recours à l'OCEC, utilisée comme mesure de transition, a permis de corriger un dysfonctionnement cardiaque grave, secondaire à une cardiomyopathie aiguë liée à la prise de méthamphétamines. La complication observée chez la patiente fait ressortir les risques associés à l'intervention et la nécessité d'une sélection rigoureuse des candidats au traitement.

Keywords: cardiomyopathy, ECMO, extracorporeal membrane oxygenation, methamphetamine, sympathomimetic

\section{INTRODUCTION}

Toxicity related to recreational drugs of abuse is a common emergency department (ED) presentation. Included in the large number of available drugs are amphetamines including amphetamine, methamphetamine, and their derivatives, which accounted for more than 20,000 exposures reported to poison centres in the United States in $2014 .^{1}$ Treatment focuses on managing the central nervous system and cardiovascular effects, including control of agitation, seizures, hyperthermia, hypertension, and more uncommonly, hypotension. This is usually achieved with the use of sedating agents and by providing hemodynamic support with intravenous (IV) fluids and more rarely, vasoactive agents. Most patients with methamphetamine toxicity are managed effectively with this approach; however, others may require more aggressive interventions. Extracorporeal membrane oxygenation (ECMO) therapy is an invasive hemodynamic support measure that has

From the *Department of Emergency Medicine, McMaster University, Hamilton, ON; †Department of Critical Care Medicine, Cumming School of Medicine, University of Calgary, Calgary, $A B$; $¥$ Poison and Drug Information Service (PADIS), Alberta Health Services, Calgary, AB; and the $\S$ Department of Emergency Medicine, University of Calgary, Calgary, AB.

Correspondence to: Dr. Laura K. Morrison, 1280 Main St W, Hamilton, ON, L8S 4K1; Email:laura.morrison@medportal.ca 
been previously used effectively for the treatment of toxicologic exposures, often initiated prior to the onset of cardiovascular collapse. ${ }^{2} \mathrm{We}$ describe a case report of a young patient with refractory cardiogenic shock and cardiac arrest secondary to severe cardiomyopathy due to methamphetamine toxicity that was effectively treated with ECMO.

\section{CASE REPORT}

A 22-year-old female was brought to the ED in cardiogenic shock. Collateral history obtained from a friend on arrival indicated that she had used IV methamphetamine and oral fentanyl three hours before this ED visit. History later obtained from the family included remote cocaine and narcotic abuse but was negative for a prior viral prodrome, fever, or cardiac disease. No naloxone was given prior to or during hospitalization.

On presentation to the $\mathrm{ED}$, vital signs included: blood pressure, $50 / 30 \mathrm{mmHg}$; heart rate, $180 \mathrm{bpm}$; temperature, $30.3^{\circ} \mathrm{C}\left(86.5^{\circ} \mathrm{F}\right)$; respiratory rate, $30 / \mathrm{min}$; and oxygen saturation, not obtainable. The patient was also wet on arrival (in October). Her friend reported placing her in a cold shower in an attempt to help at home. An examination revealed an altered level of consciousness with incomprehensible speech; cool, mottled, and cyanotic extremities; diffuse crackles on auscultation of the lungs; and no audible murmur, S3, or S4. The patient was initially given 2-3 L IV of warmed crystalloid fluids, producing an improvement in BP from approximately $50 / 30 \mathrm{mmHg}$ to $70-80$ / $40-50 \mathrm{mmHg}$. Ultimately, a total of 4-5 L of crystalloid were administered during the initial resuscitation for undifferentiated shock with minimal subsequent improvement. A trial of non-invasive positive-pressure ventilation was initiated within approximately 15-30 minutes of her arrival to prevent the need for endotracheal intubation. During this time, a chest $\mathrm{X}$-ray demonstrated pulmonary edema, central venous oxygen saturation $\left(\mathrm{ScvO}_{2}\right)$ was $30 \%$, and lactate was $12 \mathrm{mmol} / \mathrm{L}$. An electrocardiogram revealed sinus tachycardia with no overt ischemic changes. Other than metabolic acidosis with hyperlactatemia, minimal biochemical evidence of end-organ dysfunction existed on presentation (Table 1).

Prior to transfer to the intensive care unit (ICU), the patient's hemodynamic status and level of consciousness deteriorated, prompting endotracheal intubation.
Boluses of $100-300 \mathrm{mcg}$ to a total of $1000 \mathrm{mcg}$ of phenylephrine (chosen because of her significant tachycardia and its easy accessibility) were administered with minimal effect, and a norepinephrine infusion (max $16 \mathrm{mcg} / \mathrm{min}$ ) was initiated for its beta- 1 and alpha-1 effects to enhance inotropy and to ensure adequate coronary perfusion. This led to a mild improvement in blood pressure (75/50 to $100 / 80 \mathrm{mmHg}$ ). Upon transfer to the ICU, a warming blanket was applied to treat hypothermia, and rocuronium, midazolam, and fentanyl were used to control tachypnea and ventilator asynchrony. Milrinone was added to enhance biventricular inotropy and to reduce pulmonary vascular resistance and right heart afterload. We also sought to avoid further tachycardia based on the physical exam and $\mathrm{X}$-ray findings of pulmonary edema, as well as the limited point-of-care ultrasound views suggesting severe biventricular dysfunction. The patient's extremities were also cool upon palpation, suggesting elevated systemic vascular resistance. Escalating doses of a midazolam infusion were initiated to provide chronotropic improvement in the setting of sympathetic overactivity from methamphetamine, resulting in a transient heart rate reduction to $150 \mathrm{bpm}$ and a corresponding increase in blood pressure from $100 / 80 \mathrm{mmHg}$ to $150 / 105 \mathrm{mmHg}$. Vasopressors were continued, and a nitroglycerine infusion was titrated for a target mean arterial pressure of $60 \mathrm{mmHg}$ to ensure adequate coronary perfusion, but with appropriate afterload reduction. Antimicrobials were empirically started for potential aspiration pneumonia. The patient also had an abdominal radiograph performed that showed no evidence of drug packing in the bowel.

An urgent transthoracic echocardiogram confirmed severe biventricular dysfunction. The estimated left ventricular ejection fraction (LVEF) was $8 \%$ with akinesis of the proximal two-thirds of the left ventricle and a hyperdynamic apex ("reverse takotsubo sign"). Moderate mitral regurgitation was noted without any leaflet abnormalities. All other cardiac valves were normal, and there was no echocardiographic evidence of chronicity.

Along with the above measures, her vital signs and $\mathrm{Scv}_{2}$ improved (77\%), and the metabolic acidosis and hyperlactatemia resolved. After an eight-hour period of stability, the patient's lactate began to rise with no change in $\mathrm{ScvO}_{2}$. The norepinephrine and milrinone infusion rates were increased, and investigations for a non-cardiac cause (including thyroid-stimulating 


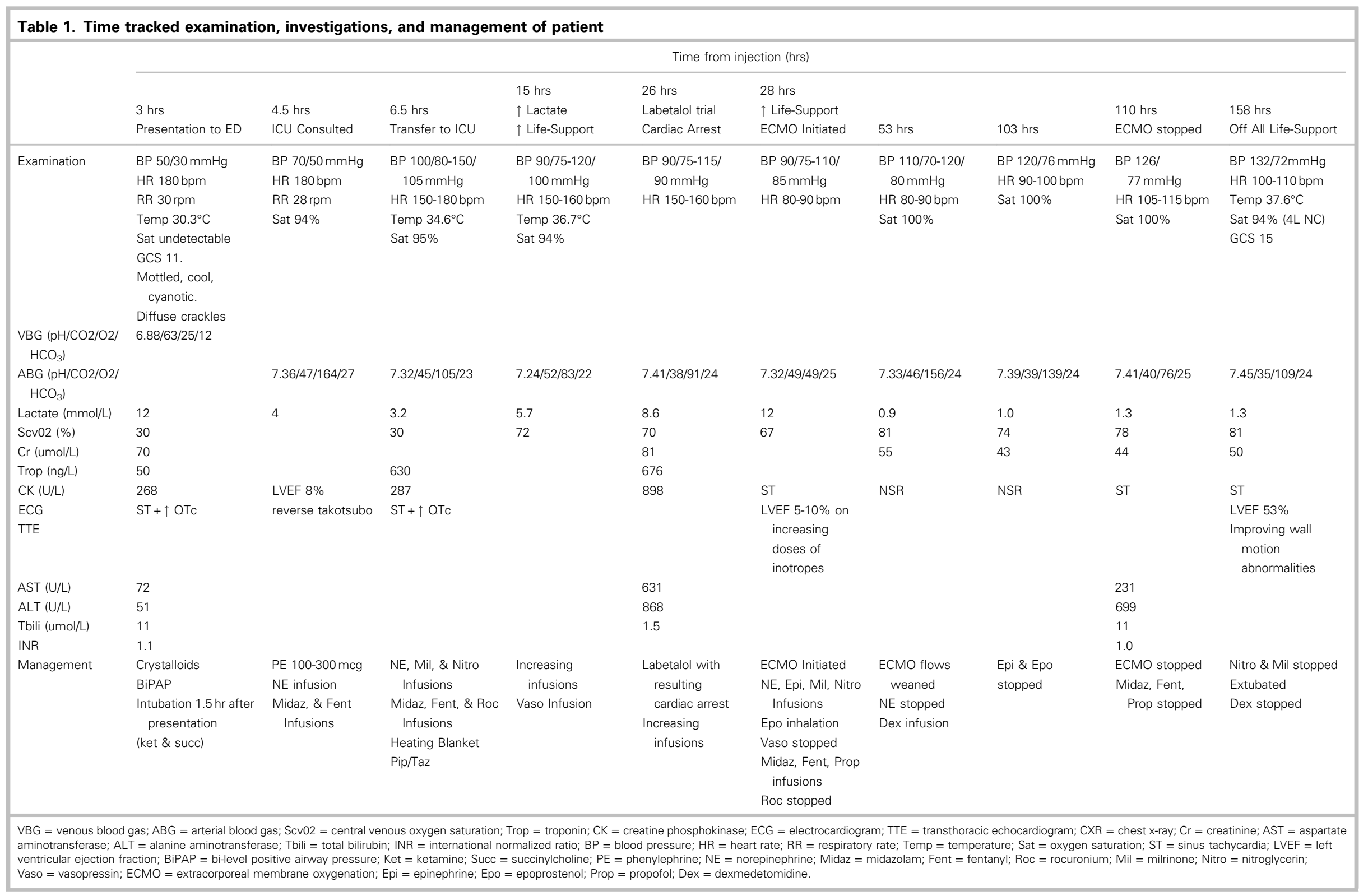


hormone, random cortisol, lipase, and point-of-care ultrasound for cardiac tamponade) were noncontributory. Given the positive but unsustained hemodynamic improvement resulting from an improved heart rate with midazolam, it was felt that the persistent tachycardia $(150 \mathrm{bpm})$ was likely contributing to the decreased cardiac output and rising lactate. As past literature has described the potential benefit of the select use of beta blockers for treating tachycardia and hypertension from acute toxicity with amphetamine and amphetamine derivatives, a small dose of labetalol $(5 \mathrm{mg})$ was administered. ${ }^{3}$ Cardiac arrest (pulseless electrical activity) ensued approximately 10 minutes later. Advanced Cardiovascular Life Support protocol was followed for five minutes with the return of spontaneous circulation. A repeat echocardiogram revealed worsening biventricular function. Clinically, severe cardiogenic shock and end-organ dysfunction persisted despite aggressive physiologic support with increasing norepinephrine $(32 \mathrm{mcg} / \mathrm{min})$, vasopressin (0.04 units/ $\mathrm{min})$, and milrinone $(40 \mathrm{mcg} / \mathrm{min})$ infusions.

Given the patient's refractory shock despite maximal support, venoarterial ECMO was initiated 25 hours after presentation. While on ECMO, inotropic support was augmented with an epinephrine infusion. Nitroglycerine was continued, and inhaled epoprostenol was added for afterload reduction of the left and right ventricles. Preload was optimized with aggressive diuresis. Norepinephrine was weaned and discontinued, and ECMO flow rates were decreased 50 hours after cannulation. Epinephrine and epoprostenol were discontinued 75 hours after cannulation. Discontinuation of ECMO occurred 82 hours after cannulation (107 hours after presentation). Infusions of milrinone and nitroglycerine were weaned off in the next 48 hours, and the patient was then successfully liberated from mechanical ventilation.

Mass spectrometry results of the urine drug screen obtained at presentation confirmed the presence of methamphetamine $(>20,000 \mathrm{ng} / \mathrm{mL})$, amphetamine $(3254 \mathrm{ng} / \mathrm{mL})$, fentanyl $(1142 \mathrm{ng} / \mathrm{mL})$, and norfentanyl $(1480 \mathrm{ng} / \mathrm{mL})$. Six days after her initial presentation, a transthoracic echocardiogram showed markedly improved biventricular function, LVEF 53\%, resolving wall motion abnormalities, and no mitral regurgitation. A repeat echocardiogram was normal 13 days post-presentation. There were no indications of neurologic dysfunction post-arrest. As a complication of ECMO cannulation, the patient experienced critical ischemia of her right leg because of a right iliofemoral thrombus, requiring embolectomy and open repair. She was discharged home with no sequelae 22 days following admission with a referral to an outpatient drug treatment program.

\section{DISCUSSION}

Amphetamine and methamphetamine abuse continues to rise. In 2011, there were nearly 160,000 ED visits in the United States related to amphetamines, accounting for $12.8 \%$ of presentations related to illicit drugs. ${ }^{4}$ Clinical manifestations related to amphetamines include agitation, diaphoresis, tachycardia, and hypertension. In many instances, patients presenting with toxicity will respond well to supportive measures, and in 2011, of all methamphetamine-related ED visits in the United States, 64\% resulted in patients being treated and released from the ED, 16\% were admitted, and 20\% led to another type of discharge (e.g., patient transfers, patient leaving against medical advice, death, etc.). ${ }^{4}$ In addition, one retrospective poison centre review found that more than $80 \%$ of methamphetamine presentations were coded as mild or moderate toxicity. ${ }^{5}$ However, significant toxicity can occur, and patients might develop rhabdomyolysis, intracerebral hemorrhage, ventricular dysrhythmias, pulmonary edema, and acute cardiac failure. ${ }^{6}$ This patient presentation specifically included features of cardiomyopathy leading to cardiogenic shock, resulting in hypotension, pulmonary edema, and altered level of consciousness on presentation, as opposed to the typical presentation as described above. In these patients, a more aggressive treatment approach is required, and in select patients with cardiomyopathy, initiation of ECMO might be warranted as a bridge to recovery.

Our patient developed a severe cardiomyopathy related to methamphetamine toxicity, a phenomenon that has been well described in medical literature. ${ }^{7}$ The reverse takotsubo (RT) pattern (with sparing of the apex accompanied by hypokinesis of the basal and mid segments) has been previously reported in patients with acute methamphetamine toxicity. ${ }^{7}$ Voskoboinik et al. recently reported on 20 patients with methamphetamineassociated cardiomyopathy and found that severe cardiac dysfunction was common, with $75 \%$ having an LVEF of $<20 \% .^{8}$ In six cases, the RT pattern was reported. All patients with RT cardiomyopathy demonstrated normalization of the LVEF within six weeks. Both the demographics and echocardiographic findings of these 
patients are consistent with this case. In patients with severe toxicity, this experience suggests that aggressive supportive care is warranted as substantial cardiac recovery was demonstrated in the majority of these cases. ${ }^{8}$ In addition, a recent case report by Stokes et al. ${ }^{9}$ describes another case of cardiogenic shock secondary to methamphetamine-induced cardiomyopathy that was treated successfully with venoarterial ECMO. In their case, the patient presented with cardiogenic shock following rapid titration of bisoprolol to manage his biventricular dysfunction. In contrast to our case, their patient had been abstinent of methamphetamine use for two months prior to presentation, suggesting a chronic cardiomyopathy and not an acute one as discussed in our case. ${ }^{9}$

As the toxic effects in most severe poisonings are temporary, providing support of oxygenation, ventilation, and hemodynamics until the drug can be eliminated might act to temporize and allow for organ recovery in these patients. Multiple published case reports of ECMO use in drug toxicity exist, and interestingly, the use of venoarterial ECMO in toxicologic cases may be associated with better outcomes, as compared with its use in other indications. ${ }^{2}$ A single case report of ECMO use in acute sympathomimetic toxicity has been reported that involved a 22 -year-old male with cardiorespiratory failure following intravenous cocaine, oral methadone, and oral benzodiazepine intoxication. ${ }^{10}$ The patient remained on ECMO for seven days with significant recovery of his cardiac function.

Although our case demonstrates the potential utility of ECMO in acute sympathomimetic-induced cardiomyopathy, it also highlights the significant adverse events that can occur with this intervention. The development of an ischemic leg requiring operative intervention is undoubtedly a serious complication and should act as a reminder of the possible sequelae of such an aggressive intervention. Prior reports suggest that leg ischemia can result from cannulation of the femoral artery in up to $21 \%$ of patients. ${ }^{11}$

Our case report has a few limitations worth noting. One potential confounding variable in our case was the concurrent presence of aspiration pneumonia, which might have contributed to septic shock and led to further hemodynamic deterioration. However, given the initial presentation of acute heart failure, confirmed methamphetamine intoxication, low $\mathrm{Scv}_{2}$, and typical echocardiography findings, a strong argument can be made for methamphetamine-induced cardiomyopathy as the primary cause of the cardiovascular collapse. In addition, the blood, urine, and sputum cultures during admission were consistently negative. Our patient also had a history of fentanyl ingestion prior to presentation but clinically did not show signs of opioid toxicity; however, it is possible that fentanyl may have contributed to myocardial depression or pulmonary edema. As mentioned, a mass spectrometry urine drug screen was done for our patient to confirm the suspected severely elevated methamphetamine level; however, this test was not part of routine clinical practice and did not contribute to individual patient care. Lastly, our case demonstrates some of the potential concerns regarding beta-blocker use. In our patient, the administration of a small dose of labetalol occurred nearly 23 hours after presentation and only after receiving appropriate treatment with vasodilatory agents. Despite previous evidence suggesting that the administration of beta blockers is a potentially safe and useful therapy in the setting of amphetamine toxicity with concomitant tachycardia and hypertension, ${ }^{3}$ our patient had an associated cardiomyopathy, and soon after the beta-blocker administration, the cardiac arrest occurred, underscoring the potential dangers of beta-blocker use in patients with significant cardiac dysfunction. In retrospect, esmolol might have been a more appropriate choice for this patient as it is shorter acting, and its $\beta 1$ selectivity could have treated the tachycardia more effectively in an already hypotensive patient. However, prior to betablocker administration, the patient's clinical course was one of progressive cardiogenic shock; despite maximal therapy including benzodiazepines, IV fluids, vasopressors, vasodilators, antibiotics, and inotropes, transition to ECMO might have been required regardless.

\section{CONCLUSIONS}

Methamphetamine toxicity can result in cardiovascular collapse and severe end-organ dysfunction. The described case demonstrates the successful use of ECMO as a bridge to recovery in acute methamphetamine-induced cardiomyopathy causing refractory cardiac failure. However, the invasiveness and potential complications associated with this intervention warrant careful patient selection in its application.

Acknowledgements: No funding was required for this toxicology observation.

Competing interests: None declared. 


\section{REFERENCES}

1. Mowry JB, Spyker DA, Brooks DE, McMillan N, Schauben JL. 2014 Annual Report of the American Association of Poison Control Centers' National Poison Data System (NPDS): 32nd Annual Report. Clin Toxicol (Phila) 2015; 53(10):962-1147.

2. de Lange DW, Sikma MA, Meulenbelt J. Extracorporeal membrane oxygenation in the treatment of poisoned patients. Clin Toxicol (Phila) 2013;51(5):385-93.

3. Richards JR, Albertson TE, Derlet RW, et al. Treatment of toxicity from amphetamines, related derivatives, and analogues: a systematic clinical review. Drug Alcobol Depend 2015;150:1-13.

4. Substance Abuse and Mental Health Services Administration. Drug Abuse Warning Network, 2011: National Estimates of Drug-Related Emergency Department Visits. 2013. Available at: http://www.samhsa.gov/data/sites/default/ files/DAWN2k11ED/DAWN2k11ED/DAWN2k11ED.pdf (accessed March 18, 2016).

5. Substance Abuse and Mental Health Services Administration. Center for Behavioral Health Statistics and Quality. The DAWN Report: Emergency Department Visits Involving Methamphetamine: 2007 to 2011; 2014. Available at: http://www.samhsa.gov/data/sites/default/files/DAWN_ SR167_EDVisitsMeth_06-12-14/DAWN-SR167-EDVi sitsMeth-2014.pdf (accessed March 18, 2016).

6. Hawley LA, Auten JD, Matteucci MJ, et al. Cardiac complications of adult methamphetamine exposures. 7 Emerg Med 2013;45(6):821-7.

7. Cruickshank CC, Dyer KR. A review of the clinical pharmacology of methamphetamine. Addiction 2009;104 (7):1085-99.

8. Voskoboinik A, Ihle JF, Bloom JE, Kaye DM. Methamphetamine-associated cardiomyopathy: patterns and predictors of recovery. Intern Med 7 2016;46(6):723-7.

9. Stokes MB, Fernando H, Taylor AJ. Cardiogenic shock secondary to methamphetamine induced cardiomyopathy requiring veno-arterial extra-corporeal membrane oxygenation. Int 7 Cardiol 2016;207:134-5.

10. De Vroey F, Plein D, Vercauteren S, Castadot M, Bettendorf P. Rescue extracorporeal circulation as bridge to recovery in fulminant cocaine-induced heart failure. Int $\mathcal{F}$ Cardiol 2009;133(3):e111-3.

11. Foley PJ, Morris RJ, Woo EY, et al. Limb ischemia during femoral cannulation for cardiopulmonary support. 7 Vasc Surg 2010;52(4):850-3. 